\title{
Does genotype-based dietary advice elicit a change in dietary intake? Focus on hypertension and salt intake
}

\author{
S.J. Cogbill*, P.K. Louca*, L. Pilic and Y. Mavrommatis \\ Faculty of Sport, Health and Applied Science, St Mary's University Twickenham TW1 4SX, UK
}

Hypertension affects around 1 billion people worldwide ${ }^{(1)}$. Salt sensitivity, a heterogenous blood pressure response to dietary salt, is a risk factor for hypertension and cardiovascular mortality. In the UK adults, it has been associated with variations in the $S L C 4 A 5$ gene coding for sodium cotransporter. A single nucleotide polymorphism (SNP) in this gene, rs10177833, has also been associated with increased salt intake $^{(2)}$. Genetics-based personalised nutrition may positively impact health behaviours aiding in the prevention of chronic disease ${ }^{(3)}$. However, literature is currently non-ubiquitous regarding anticipated dietary behaviour responses ${ }^{(3,4)}$ potentially owing to the target's understanding of risks and benefits and interpretation of results. Therefore, it is necessary to understand whether genetic literacy and knowledge of increased genetic risk influence behaviour change. The aim of this study was to analyse the impact of communicating genetic susceptibility to salt sensitivity on salt intake and understand if genetic literacy may also influence dietary changes.

This study, approved by the St Mary's University ethics committee, included 32 UK adults (eight males and 24 females) with an average age of 27 years and body mass index ranging from $18.4-30.4 \mathrm{~kg} / \mathrm{m}^{2}$. Participants were predominantly Caucasian from all educational backgrounds. Participants completed a 24-hour dietary recall and a genetic literacy and attitude questionnaire (Public Understanding and Attitudes towards Genetics and Genomics questionnaire) at baseline. Participants were then genotyped and categorised into high- and low-risk groups based on the SLC4A5rs10177833. Personalised nutritional feedback was provided based on genotype and sent electronically, mimicking that of direct to consumer genetic tests. Those considered high risk (AA/AC) were advised to consume no more than $4 \mathrm{~g}$ salt/day, and low risk (CC) were provided with the government guideline (6g/d). At a four-week follow-up, a second dietary recall was taken.

Statistical significance was set at $\mathrm{p}<0.05$. Overall, the proportion of individuals adhering to the government guidelines for salt intake did not change post-intervention (McNemar's test, $\mathrm{p}=0.388$, Figure 1.). Moreover, salt intake did not significantly change post knowledge of genotypes (Two-way mixed ANOVA, $\mathrm{p}=0.661$, Table 1). Of 31 participants, 45\% had high genetic literacy and $78 \%$ had a favourable attitude towards genetics. There was no interaction between genotype and genetic literacy on the change in salt intake (Two-way ANOVA, $\mathrm{p}=0.085$ ).

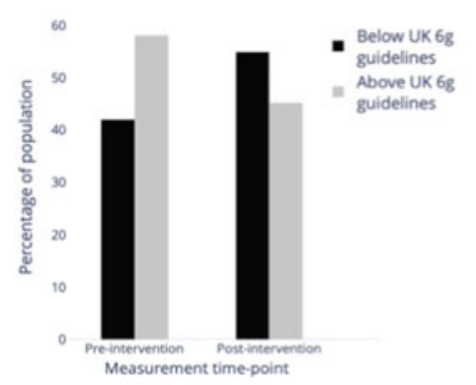

\begin{tabular}{|c|c|c|c|c|}
\hline & \multicolumn{4}{|c|}{ Genotype groups } \\
\hline & \multicolumn{2}{|c|}{ High risk $(n=20)$} & \multicolumn{2}{|c|}{ Low risk $(n=8)$} \\
\hline & Mean & S.D & Mean & S.D \\
\hline $\begin{array}{l}\text { 'Pre-intervention } \\
\text { sodium intake } \\
\text { (mg/1000kcal/day) }\end{array}$ & 1333 & 612 & 1495 & 620 \\
\hline $\begin{array}{l}\text { 'Post-intervention } \\
\text { sodium intake } \\
\text { (mg/1000kcal/day) }\end{array}$ & 1078 & 378 & 1369 & 420 \\
\hline
\end{tabular}

Fig. 1. Percentage of population above and below current $6 \mathrm{~g}$ salt guidelines pre- and post-intervention $(\mathrm{McNemar}$ 's test, $\mathrm{P}=0.388$ ).

\begin{tabular}{llllll}
\hline & \multicolumn{4}{c}{ Genotype groups } \\
\cline { 2 - 4 } & \multicolumn{2}{c}{ High risk $(n=20)$} & & Low risk $(n=8)$ \\
\cline { 2 - 4 } & Mean & S.D & & Mean & S.D \\
\hline †Pre-intervention sodium intake $(\mathrm{mg} / 1000 \mathrm{kcal} / \mathrm{day})$ & 1333 & 612 & 1495 & 620 \\
†Post-intervention sodium intake (mg/1000kcal/day) & 1078 & 378 & & 1369 & 420 \\
\hline Non-significant interaction between risk/non-risk genotypes pre and post-intervention (Two-way mixed ANOVA, $\mathrm{p}=0.661)$.
\end{tabular}

This data suggests that genotype-based dietary advice for salt reduction does not elicit short-term dietary behaviour changes in younger UK adults with an overall positive attitude towards genetics. Longer duration studies are vital to determine if genetic literacy influences dietary behaviour over time.

1. Abreu D, Sousa P, Matias-Dias C et al. (2018) BMC Public Health 18, 722.

2. Pilic L, Mavrommatis Y (2018) Br J Nutr 120, 721-731.

3. Nielsen DE, El-Sohemy A (2014) PLOS ONE 9, e112665.

4. Celis-Morales C, Livingstone KM, Marsaux CF et al. (2017) Int J Epidemiol 46, 578-88.

*S.J. Cogbill and P.K. Louca are the co-first authors 